\title{
Предварительные результаты исследований донных отложений арктического озера Фара, Западный Шпицберген
}

\author{
Даувальтер В.А. ${ }^{1}$, Мещеряков Н.И. ${ }^{2}$, Усягина И.С. ${ }^{2}$, Духно Г.Н. ${ }^{2}$, Шарин В.В. ${ }^{3,4}$, \\ Слуковский 3.И. ${ }^{5}$ \\ ${ }^{1}$ Институт проблем промыпиленной экологии Севера КНЦ PAH, Anamumbl, vladimir@inep.ksc.ru \\ ${ }^{2}$ Мурманский морской биологический институт РАН, Мурманск \\ ${ }^{3}$ Полярная морская геологоразведочная экспедичия, Санкт-Петербург - Ломоносов \\ ${ }^{4}$ Санкт-Петербургский государственный университет, Санкт-Петербург \\ ${ }^{5}$ Институт геологии КарНЦ РАН, Петрозаводск
}

Аннотация. Приведены результаты предварительных исследований донных отложений арктического озера Фара, расположенного на западном побережье острова Западный Шпицберген вблизи заброшенного шахтерского поселка Грумант. В пробах донных отложений проведен гранулометрический анализ и определение потерь при прокаливании (ППП), как косвенного показателя содержания органического материала. По результатам гранулометрического анализа установлено, что в донных отложениях оз. Фара преобладает пелитовая и алевритовая фракции. Распределение гранулометрических типов осадков в оз. Фара соответствует идеальной схеме сортировки материала, при которой от периферии бассейна к его центру идет постепенное уменьшение размера частиц. Значения ППП в донных отложениях находятся в небольшом диапазоне от 5.4 до 8.8 \%, причем максимальная величина зафиксирована в прибрежных станциях, что нехарактерно для озерных отложений. Незначительные величины ППП могут говорить об угнетающем антропогенном влиянии на экосистему озера.

Ключевые слова: арктическое озеро, Шпицберген, донные отложения, гранулометрический состав, органическое вещество.

\section{Preliminary results of studying sediments of Arctic Lake Fara, West Spitsbergen}

\author{
Dauvalter V.A. ${ }^{1}$, Meshcheryakov N.I. ${ }^{2}$, Usyagina I.S. ${ }^{2}$, Dukhno G.N. ${ }^{2}$, Sharin V.V. ${ }^{3,4}$, Slukovsky Z.I. ${ }^{5}$ \\ ${ }^{1}$ Institute of North Industrial Ecology Problems Kola SC RAS, Apatity, vladimir@inep.ksc.ru \\ ${ }^{2}$ Murmansk Marine Biological Institute, RAS, Murmansk \\ ${ }^{3}$ Polar Marine Exploration Expedition, St. Petersburg - Lomonosov \\ ${ }^{4}$ Saint Petersburg State University, St. Petersburg \\ ${ }^{5}$ Institute of Geology, Karelia RC RAS, Petrozavodsk
}

\begin{abstract}
The article presents results of preliminary studies of the sediments of Arctic Lake Fara on the western coast of the Island Western Spitsbergen near the abandoned coal mining village Grumant. Particle size analysis and determination of loss on ignition (LOI), as an indirect index of the organic material content, were carried out in sediment samples. According to the results of the particle size analysis, pelitic and aleuritic fractions predominate in the Lake Fara sediments. The distribution of the granulometric types of sediments in Lake Fara corresponds to the ideal scheme for sorting material, in which a gradual decrease in particle size occurs from the periphery of the basin to its center. The LOI values in sediments vary from 5.4 to $8.8 \%$, with the maximum value recorded at coastal stations, which is not typical of lake sediments. Insignificant LOI values may indicate a depressing anthropogenic effect on the lake ecosystem.
\end{abstract}

Key words: Arctic lake, Spitsbergen, sediments, granulometric composition, organic matter.

Растущая обеспокоенность состоянием окружающей среды Арктики, которая еще в начале XX века оставалась одной из самых нетронутых результатами антропогенной деятельности в мире, вызывает необходимость проведения комплексных исследований водных и наземных экосистем Арктики для оценки их современного экологического состояния. Вследствие усиливающегося освоения природных ресурсов Арктики в последние годы антропогенная нагрузка на окружающую среду с каждым годом будет только нарастать. Например, на Шпицбергене относительно долгая история 
добычи угля (начиная с конца девятнадцатого века) заставляет учитывать состояние окружающей среды не только в настоящее время, но и до недавней деятельности человека (Rose et al., 2004). Учитывая сохраняющийся потенциал эксплуатации ископаемого топлива на Шпицбергене (Holte et al., 1996), проведение комплексных экологических исследований на Шпицбергене, как одной из наиболее индустриально освоенных территорий в высоких широтах Арктики, является вдвойне важным.

Одной из важных проблем является установление влияния трансграничного и локального атмосферного загрязнения на состояние арктических экосистем. Проведенными исследованиями (Rose et al., 2004) установлено, что в современных донных отложениях озер Шпицбергена присутствуют значительные количества сфероидальных углеродистых частиц и антропогенных органических загрязнителей, что говорит об усиливающемся загрязнении Арктики. Выявление загрязнения Арктических территорий тяжелыми металлами усложняется из-за их поступления из природных источников, например, из почв и горных пород. Естественные потоки тяжелых металлов в озера контролируются биогеохимическим циклом на водосборном бассейне, который может изменяться как в результате естественных изменений, так и в результате воздействия человека. Поэтому, для правильной интерпретации результатов исследования содержания химических элементов в озерных отложениях необходимо понимать изменения, происходящие в самих озерах и на водосборном бассейне за последние годы. Известно, что поток тяжелых металлов в Арктику в наше время увеличился: со времен промышленной революции наблюдается заметное увеличение концентрации и накопления тяжелых металлов в ледниковых щитах (Boutron et al., 1995; Hong et al., 1996). Но это увеличение незначительно, и нет уверенности в том, что заметное воздействие будет наблюдаться в озерных экосистемах. Например, было обнаружено (Rognerud et al., 1998), что в поверхностных слоях донных отложений озер Шпицбергена происходит значительное повышение концентраций только Нg по сравнению с ее доиндустриальными содержаниями, также как и $\mathrm{Pb}$, но это увеличение не столь значительно.

В толще донных отложений оз. Болтерскардет, расположенного в 10 км на восток от шахтного поселка Грумант, среди исследованных тяжелых металлов ( $\mathrm{Pb}, \mathrm{As}, \mathrm{Cd}, \mathrm{Cu}, \mathrm{Cr}, \mathrm{Co}, \mathrm{Ni}$ и $\mathrm{Sn}$ ) только $\mathrm{Pb}$ показывает значительное увеличение концентраций от нижних частей к верхним частям колонки (Sun et al., 2006). Обнаружено также увеличение антропогенного потока Рb в вертикальном распределении. Антропогенные потоки Рb были относительно низкими до 1945 г., т.е. до конца Великой отечественной войны - около 0.7 мкг/( $\mathrm{cm}^{2} \cdot$ год), после 1945 г. отмечалось более чем двукратное увеличение потока $\mathrm{Pb}$ со средним значением 1.8 мкг/( $\mathrm{cm}^{2} \cdot$ год). В период между 1980-ми и 1990-ми годами произошло резкое увеличение потока $\mathrm{Pb}$ до среднего значения 5.9 мкг/( $\mathrm{cm}^{2} \cdot$ год). Изменение потоков антропогенного $\mathrm{Pb}$ до 1970 года в оз. Болтерскардет показывает картину, сходную с данными в ледниковых щитах Гренландии (Boutron et al., 1995). Таким образом, в течение последних двух десятилетий в оз. Болтерскардет наблюдается быстро увеличивающаяся тенденция антропогенных потоков $\mathrm{Pb}$. Это говорит о том, что местная антропогенная деятельность (например, сжигание угля) сыграла важную роль в увеличении антропогенного потока $\mathrm{Pb}$ в последние два десятилетия. Увеличение содержания тяжелых металлов в донных отложениях водоемов, вероятно, является результатом загрязнения за счет трансграничного переноса, так и местного происхождения. Поэтому необходимы дальнейшие исследования содержания тяжелых металлов в донных отложениях Арктических водоемов, чтобы выявить тенденции изменения антропогенной нагрузки на эти очень чувствительные к любым нагрузкам экосистемам. На это и направлены исследования донных отложений водоемов Шпицбергена, предварительные результаты которых приводятся в данной публикации.

Пробы донных отложений из оз. Фара (норвежское название озера Тенндаммен) были отобраны летом 2018 г. дночерпателем Питерсена на 7 станциях (рис. 1, 2). Отбирался поверхностный 2-см слой донных отложений для дальнейших исследований. Глубина на станциях отбора проб была примерно одинаковой по всему озеру и находилась в пределах 1.5-1.6 м. Для озера характерна округлая форма, свал глубин недалеко от берега резкий, радиус озера примерно 250 м. Вследствие незначительной глубины озеро зимой промерзает до дна, и в течение короткого арктического лета в нем не должно происходить сортировки и отделения мелких фракций и транспорт их в цен- 


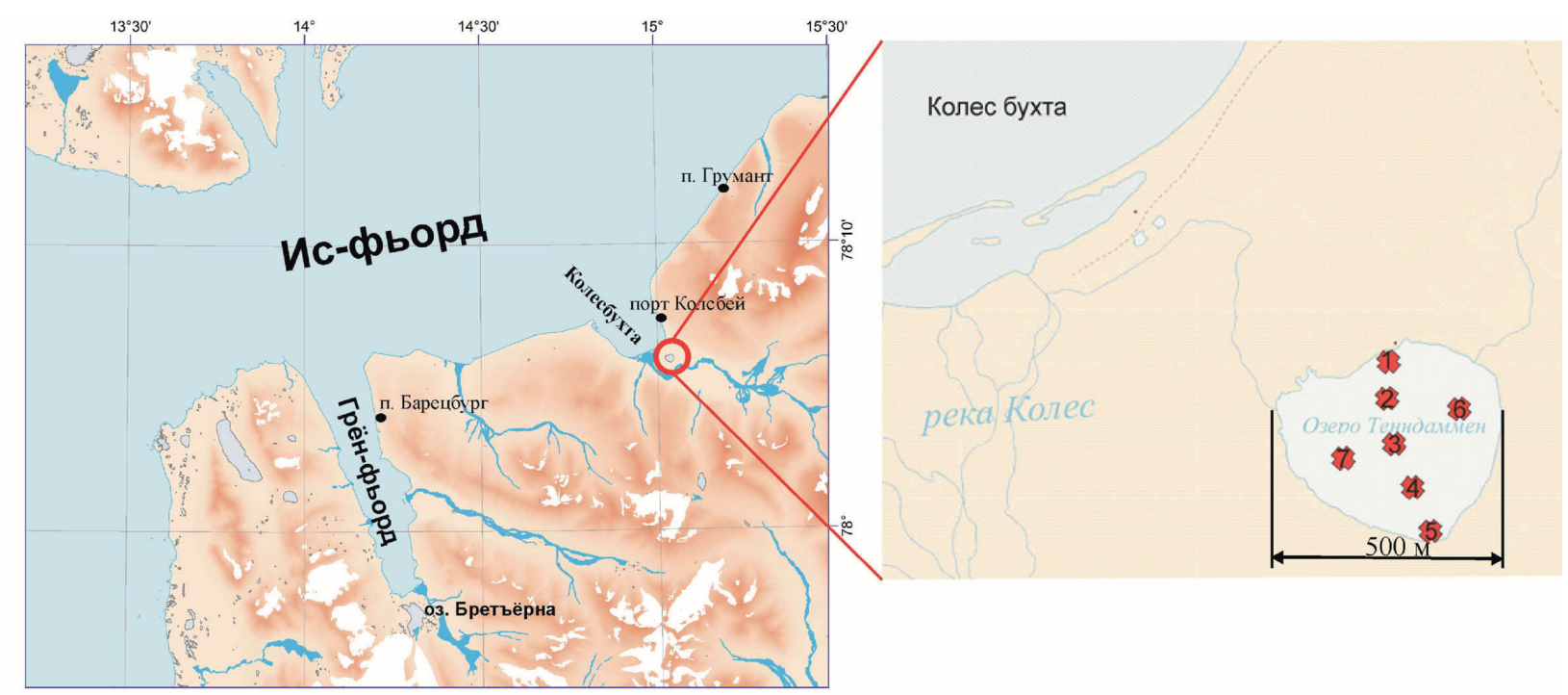

Рис. 1. Карта-схема станций отбора проб донных отложений в озере Фара (Тенндаммен).

Fig. 1. Map of sampling stations of sediments in Lake Fara (Tenndammen).

тральные акватории озеро. Координаты озера $-78^{\circ} 06^{\prime}$ с.ш. и $15^{\circ} 02^{\prime}$ в.д., площадь озера 0.15 км²,

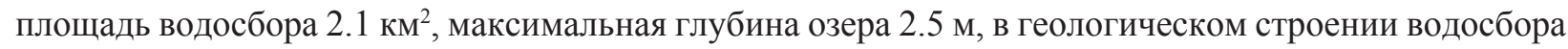
озера принимают участие современные морские отложения, а также песчаники и глинистые сланцы палеоцен-эоценового возраста (Boyle et al., 2004).

В 10 км от озера на северо-восток расположен российский шахтерский поселок Грумант (норв. Grumantbyen). Свое название поселок получил из-за старого поморского названия Шпицбергена - Грумант. В поселке Грумант с 1931 г. Государственным трестом «Арктикуголь» производилась добыча угля, но из-за отсутствия глубоководного порта его погрузка на суда происходила в порту Колсбей, куда вела железная дорога. За время своего существования трест «Арктикуголь» добыл на руднике Грумант 2 млн. тонн угля. В 1961 г. было принято решение о консервации, и по-

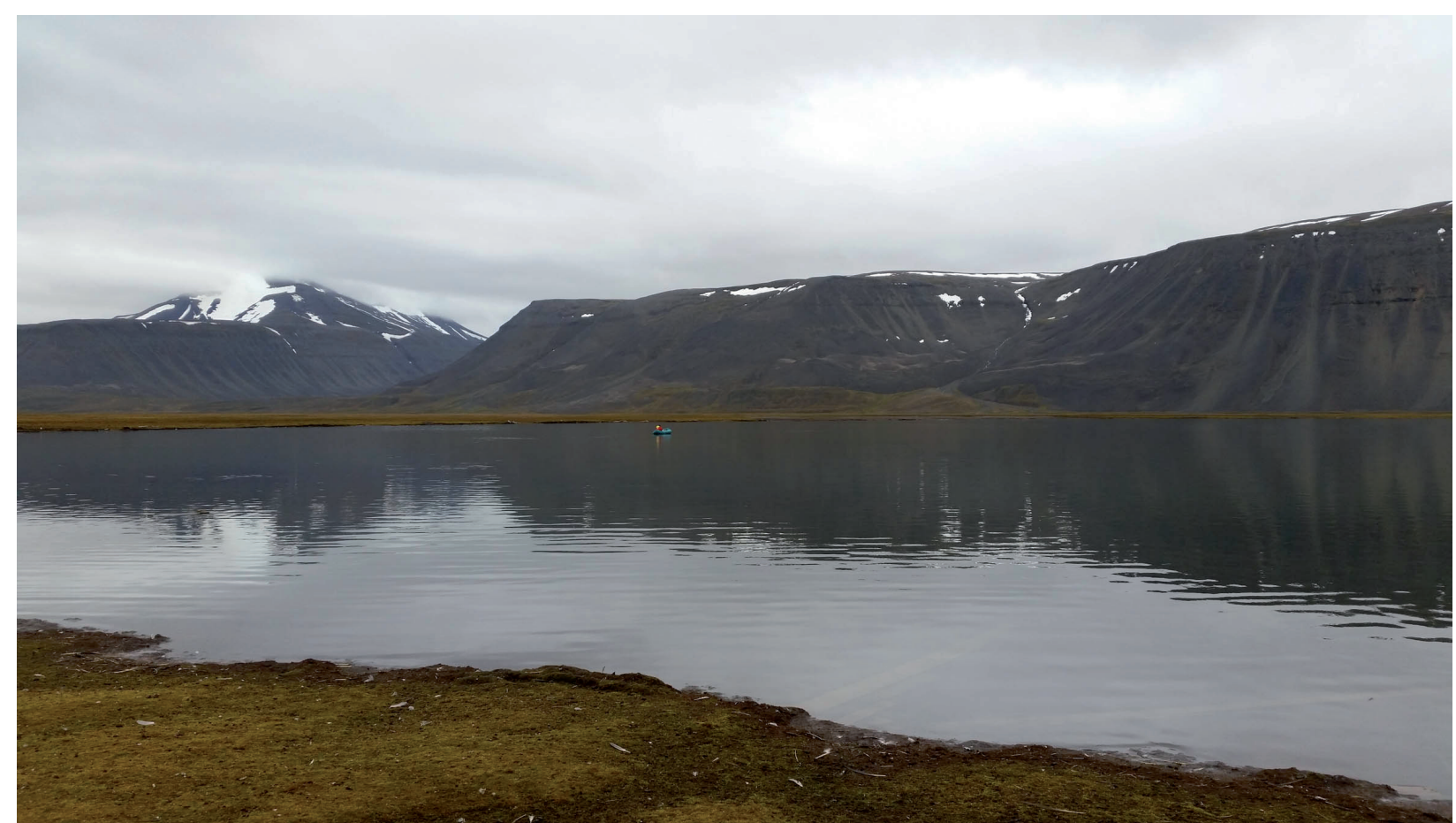

Рис. 2. Вид на оз. Фара (Тенндаммен).

Fig. 2. View of Lake Fara (Tenndammen). 
следние тонны грумантского угля были выданы 15 июля того же года. Географическое положение поселения, зажатого между фьордом и горой, не позволяло организовать строительство жилья, поэтому большинство шахтеров проживало в поселке Колсбей, который находится около исследуемого оз. Фара. На берегу водоема остались постройки, которые в настоящее время разрушены. Поэтому озеро испытывало довольно интенсивную антропогенную нагрузку, что может проявиться в увеличении содержания микроэлементов, в том числе и тяжелых металлов в поверхностных частях донных отложений.

В настоящее время железная дорога в сторону пос. Колсбей находится в полной негодности, туннель в сторону Груманта засыпан. В самом пос. Грумант находятся несколько аварийных зданий советского времени, непригодных для эксплуатации. В 1981 г. было принято решение о доразведке Грумантского месторождения. Разведанные запасы угля сейчас оцениваются более чем в 100 млн. тонн. Этот факт неоднократно использовался руководством концерна Арктикуголь для объявления о проектах возобновления добычи угля на разрезе. Учитывая, что кроме строительства шахты для этого потребуется восстановление туннеля, железной дороги и порта Колсбей, экономическая целесообразность проекта остается под вопросом. Но не исключено, что в дальнейшем, возможно, будет принято решение о возобновление добычи угля, и антропогенная нагрузка на оз. Фара продолжится.

На данный момент в отобранных на оз. Фара пробах донных отложений проведен гранулометрический анализ и определены потери при прокаливании (ППП), как косвенный показатель содержания органического материала, результаты которых освещаются в данной статье. Гранулометрический анализ проб проводился в лаборатории ММБИ РАН по методике Батурина-Осборна. Для определения ППП сухую навеску для выделения в ней терригенной составляющей подвергали прокаливанию в муфельной печи в течение 4 -х часов при температуре $450^{\circ} \mathrm{C}$ до постоянного веса (Даувальтер, 2012). В дальнейшем доведенная до комнатной температуры навеска вновь взвешивалась, тем самым устанавливали в ней соотношение органического и минерального вещества. Результаты гранулометрического анализа и определения ППП показаны в таблице.

Таблица. Гранулометрический состав и потери веса при прокаливании (ППП) донных отложений озера Фара (Тенндаммен), \%, значения коэффициента корреляции ППП и гранулометрических фракций (r).

Table. Granulometric composition and loss on ignition (LOI) of sediments of Lake Fara (Tenndammen), $\%$, the values of the correlation coefficient of the LOI and particle size fractions (r).

\begin{tabular}{|c|c|c|c|c|c|c|c|c|c|}
\hline \multirow{2}{*}{ Станции } & \multirow{2}{*}{$\begin{array}{l}\text { ППП } \\
\text { LOI }\end{array}$} & $>2$ & $1-2$ & $1-0.5$ & $0.5-0.25$ & $0.25-0.1$ & $0.1-0.05$ & $0.05-0.01$ & $<0.01$ \\
\hline & & \multicolumn{8}{|c|}{ MM } \\
\hline 1 & 8.8 & 1.7 & 3.0 & 14.9 & 10.7 & 12.3 & 8.9 & 14.0 & 34.5 \\
\hline 2 & 7.5 & 0.0 & 0.1 & 0.3 & 1.2 & 4.5 & 2.4 & 7.5 & 84.0 \\
\hline 3 & 6.7 & 0.0 & 0.1 & 1.3 & 1.2 & 4.2 & 6.8 & 18.1 & 68.3 \\
\hline 4 & 5.5 & 0.0 & 0.0 & 0.0 & 0.2 & 1.0 & 4.1 & 39.5 & 55.2 \\
\hline 5 & 5.4 & 16.7 & 7.2 & 4.0 & 2.2 & 2.6 & 7.0 & 33.1 & 27.2 \\
\hline 6 & 6.0 & 0.0 & 0.1 & 0.5 & 1.0 & 5.3 & 2.1 & 18.5 & 72.5 \\
\hline 7 & 8.8 & 0.0 & 0.0 & 0.6 & 1.8 & 10.9 & 9.7 & 49.5 & 27.5 \\
\hline \multicolumn{2}{|r|}{0.0} & -0.42 & -0.24 & 0.46 & 0.59 & 0.92 & 0.57 & -0.08 & -0.25 \\
\hline
\end{tabular}

По результатам гранулометрического анализа установлено, что в донных отложениях оз. Фара в целом преобладает пелитовая и алевритовая фракции с примесью разнозернистого песка. В донных отложениях со станции 5 (южный мелкий берег) присутствуют включения гравийно-галечных зерен. В донных отложениях озера присутствует уголь, особенно в донных отложениях станции 1 (северный берег). Несмотря на небольшую глубину озера и то, что озеро в зимнее время промерзает до дна, в нем происходит сортировка частиц донных отложений по гранулометрическим фракциям в результате, главным образом, волновой деятельности, выражающейся в том, что в центральной части озера (станции 2-4, а также 6) преобладает тонкодисперсная пелитовая и алевритовая фракция (размером $<0.01$ мм), доля которой составляет на этих станциях от 55 до 84 \%. На этих станциях практически отсутствуют фракции грубого и крупного песка и появляется незначитель- 
ная доля среднего и мелкого песка (первые единицы), увеличивается доля алевритовой фракции (от 10 до 40 \%). В донных отложениях станций, расположенных ближе к берегу, уменьшается доля пелитовой фракции, но увеличивается алевритовой и псаммитовой (таблица). Таким образом, распределение гранулометрических типов осадков в оз. Фара соответствует идеальной схеме течения процессов сортировки и осаждения материала, при котором от периферии бассейна к его центру идет постепенное уменьшение размера частиц, слагающих осадки (Страхов и др., 1945).

Значения ППП в донных отложениях оз. Фара невелики для озерных отложений северных и арктических территорий (Даувальтер, 2012) и находятся в небольшом диапазоне от 5.4 до 8.8 \% (таблица), причем максимальная величина зафиксирована в прибрежных станциях 1 и 7, что нехарактерно для озерных отложений, где, как правило, в более тонкодисперсных отложениях отмечаются более высокие величины ППП (Даувальтер, 2012). Наименьшее значение ППП зафиксировано на станции 5, в донных отложениях которой присутствует довольно большая доля гравийно-галечных зерен (17\%). Проведенный корреляционный анализ показал достоверную высокую связь органического материала с мелко-песчаной фракцией $(\mathrm{r}=0.92)$, что также нехарактерно для озерных отложений. Менее значимые величины коэффициента корреляции были выявлены для средне-песчаной и алевритовой фракций ( $\mathrm{r}=0.59$ и 0.57 соответственно). Незначительные величины ППП могут говорить о не очень активной биологической деятельности в самом озере (за счет чего образуется автохтонный органический материал) и на территории его водосбора (аллохтонный материал), что характеризует суровые арктические условия. Возможно, незначительные величины ППП являются отражением угнетающего антропогенного влияния на экосистему озера. Ответы на эти вопросы будут даны в результате дальнейших геохимических и гидробиологических исследований озера, которые будет проведены в ближайшее время.

Работа выполнена в рамках темы НИР №0226-2019-0045, госзадания «Комплексные исследования экосистем фьордов и морей, омывающих архипелаг Шпицберген» и частично поддержана из средств гранта РФФИ (18-05-60125).

\section{Литература}

1. Даувальтер В.А. Геоэкология донных отложений озер. Мурманск: Изд-во Мурманского гос. техн. ун-та, 2012. $242 \mathrm{c}$.

2. Страхов Н.М. О сравнительно-литологическом направлении и его ближайших задачах // Бюлл. Моск. о-ва испытателей природы. Отд-е геологии. 1945. № 3-4.

3. Boutron C.F., Candelone J.P., Hong S.M. Greenland snow and ice cores - unique archives of large-scale pollution of the troposphere of the northern-hemisphere by lead and other heavy-metals // Science of the Total Environment. 1995. V. 161. P. 233-241.

4. Boyle J.F., Rose N.L., Appleby P.G., Birks H.J.B. Recent environmental change and human impact in Svalbard: the lake-sediment geochemical record // Journal of Paleolimnology. 2004. V. 31. P. 515-530.

5. Holte B, Dahl S., Gulliksen B. and Næs K. Some macrofaunal effects of local pollution and glacier-induced sedimentation, with indicative chemical analyses, in the sediments of two Arctic fjords // Polar Biology. 1996. V. 16. P. 549-557.

6. Hong S.M., Candelone J.P., Soutif M., Boutron C.F. A reconstruction of changes in copper production and copper emissions to the atmosphere during the past 7000 years // Science of the Total Environment. 1996. V. 188. P. 183-193.

7. Rognerud S., Skotvold T., Fjeld E., Norton S.A., Hob K.A. Concentrations of trace elements in recent and preindustrial sediments from Norwegian and Russian Arctic lakes // Canadian Journal of Fisheries and Aquatic Science. 1998. V. 55. P. 1512-1523.

8. Rose N.L., Rose C.L., Boyle J.F., Appleby P.G. Lake-sediment evidence for local and remote sources of atmospherically deposited pollutants on Svalbard // Journal of Paleolimnology. 2004. V. 31. P. 499-513.

9. Sun Q., Chu G., Liu J., Gao D. A 150-year Record of Heavy Metals in the Varved Sediments of Lake Bolterskardet, Svalbard // Arctic, Antarctic, and Alpine Research. 2006. V. 38, No. 3. P. 436-445. 